\title{
A case for an integrative view on affect regulation through media usage
}

\author{
Schramm, H ; Wirth, Werner
}

\begin{abstract}
Zillmann's mood-management theory (Zillmann, 1988) has acquired a prominent place in media psychology and makes reliable predictions about people's hedonistically motivated mood regulation via entertainment offerings. However, the full potential for explaining affect regulation through media usage has not been exhausted so far. Therefore, we aim at an integrative view of the field based on empirical findings from communication studies as well as on the background of contemporary theories of mood (regulation) and emotion (regulation). The purpose of this analysis is to argue towards an integrative theoretical perspective which considers both unconscious and conscious/reflected processes of affect regulation through media, supplements the hedonistic motive with other non-hedonistic, instrumental motives of affect regulation, looks at selection behavior as well as at other behavioral and cognitive strategies of affect regulation, and encompasses individual attributes (particularly those with affinity to affects).
\end{abstract}

DOI: https://doi.org/10.1515/COMMUN.2008.002

Posted at the Zurich Open Repository and Archive, University of Zurich

ZORA URL: https://doi.org/10.5167/uzh-12141

Journal Article

Published Version

Originally published at:

Schramm, H; Wirth, Werner (2008). A case for an integrative view on affect regulation through media usage. Communications: The European Journal of Communication Research, 33(1):27-46.

DOI: https://doi.org/10.1515/COMMUN.2008.002 


\title{
A case for an integrative view on affect regulation through media usage
}

\author{
HOLGER SCHRAMM and WERNER WIRTH
}

\begin{abstract}
Zillmann's mood-management theory (Zillmann, 1988) has acquired a prominent place in media psychology and makes reliable predictions about people's hedonistically motivated mood regulation via entertainment offerings. However, the full potential for explaining affect regulation through media usage has not been exhausted so far. Therefore, we aim at an integrative view of the field based on empirical findings from communication studies as well as on the background of contemporary theories of mood (regulation) and emotion (regulation). The purpose of this analysis is to argue towards an integrative theoretical perspective which considers both unconscious and conscious/reflected processes of affect regulation through media, supplements the hedonistic motive with other non-hedonistic, instrumental motives of affect regulation, looks at selection behavior as well as at other behavioral and cognitive strategies of affect regulation, and encompasses individual attributes (particularly those with affinity to affects).
\end{abstract}

Keywords: communication theory, mood management, emotion, emotion regulation, reception processes, media selection, media use

Over the past twenty years, Zillmann's mood-management theory (1988; abbreviated as "MMT") has acquired a central and prominent place in media psychology (Oliver, 2003). Primarily, it explains why people turn to the media for mood regulation and proposes which media offerings they are likely to select depending on their mood state. Essentially, MMT explains the selection of media offerings and is empirically wellsupported. Both results from laboratory experiments as well as results from studies with a quasi-experimental or a correlative design have con- 
tributed to the empirical validation of its central propositions (for reviews cf. Oliver, 2003; Schramm, 2005).

However, not all findings from other studies on mood and emotion regulation through media usage can be explained by MMT. In some instances, either minimal mood improvement was observed or media selection and mood improvement were dependent on specific individual factors (e. g., Mares and Cantor, 1992; Oliver, 1993; Oliver, Weaver, and Sargent, 2000; Schramm, 2005). Even in studies that were conducted under the MMT paradigm, differences in media selection between experimental conditions (e. g., positive vs. negative mood) were often in accordance with the theory only on a relative, but not on an absolute basis. For example, in an experiment conducted by Knobloch and Zillmann (2002), subjects in a negative mood selected more happy media offerings than sad ones, which was in accordance with the theory. However, subjects in a positive mood-state selected more sad music than happy music, which was not predicted by the theory to this extent. Bringing to mind the variety of results in studies on mood/emotion (regulation) as effect of media consumption (for reviews cf. Cantor, 2002; Sparks and Sparks, 2002; Weaver and Tamborini, 1996; Wirth and Schramm, 2005), it becomes apparent that MMT can predict certain emotional effects very well, while other effects need additional theoretical explanations. To overcome this theoretical shortage and to broaden the theoretical perspective on this research field, we need to look first at the milestones of MMT, including Zillmann's additional assumptions and annotations in later publications (e. g., Zillmann, 1998, 2000). By doing this, we assume to point up the explanatory power of MMT in a certain area and - at the same time - to clarify what aspects have to be explained by other theoretical approaches.

\section{Mood-Management Theory}

MMT, with its various hypotheses, is based on two hedonistic premises. First, individuals tend to avoid or terminate aversive stimulations/moods of any kind or to reduce their intensity at any time. Secondly, they correspondingly tend to maintain gratifying or pleasurable stimulations/ moods or to increase their intensity (Zillmann, 1988). Proposition three of his theory is of central importance for media usage: The more the external stimulus arrangement is restricted to entertainment usage, the more the individual takes advantage of these offerings in order to minimize unpleasant aversive stimulations/moods and to maximize pleasurable stimulations/moods; in terms of temporal duration as well as of intensity. As these premises and propositions set the frame for the whole 
theory, all subsequent hypotheses of MMT are restricted to hedonistically motivated regulation processes.

In Zillmann's opinion (2000), the central paradigm of his theory is still the more or less automatic managing of moods through the selection and usage of media entertainment offerings via operant learning: People normally turn their attention to those media programs with which they have had positive experiences in the past, thus, which had a positive effect on their moods. By experiencing this positive effect again and again, people learn to choose the same media programs in comparable situations without being aware of it.

According to Zillmann (2003), even emotions develop more or less automatically, mostly without participation of the neocortex, and are relatively independent of reflective thinking or conscious processing. ${ }^{1}$ Zillmann denies the necessity of cognitive thinking for emotional reactions, but assumes that all activities are at least under the control of continuous cognitive monitoring. On the other hand, he conceptualizes mood as an experience "characterized by the absence of targeted, consummatory behavior" (Zillmann, 2003, p. 551). That is why MMT is restricted to mostly automatic and unconscious mood regulation processes.

Apart from that, MMT is based on assumptions of the two-factor model of emotion by Schachter and Singer (1962). The fundamental idea is that affect (mood and emotion) is merely the product of attribution of arousal that is produced by external stimuli. All these considerations underestimate the importance of 'internally produced' cognitions and the person's own deliberative strategies concerning the formation and regulation of mood, and it becomes evident why MMT is focused on the configuration of externally available stimuli as the fundamental strategy for changing mood states.

As a last milestone, Zillmann differs between entertainment and information/education offerings with respect to their mood managing power: According to Zillmann, the well-considered usage of entertainment offerings motivated by their informative/instrumental benefit is of secondary importance. As for the usage of informational and educational offerings, however, Zillmann regards instrumental goals of primary importance. Here, short-run hedonistic motives like immediate mood improvement can recede to the background because recipients consciously focus on a content of high educational value, which will hopefully help them deal with life more effectively in the future. Thus, the usage of 'negative' stressful media offerings can also be explained (see also Zillmann, 1998).

In summary, according to Zillmann, mood regulation is hedonistically motivated and results in a spontaneous, unreflected selection of primary entertainment offerings, whereas in non-hedonistic media usage, the ben- 
efit associated with information for one's own life is of utmost importance. This results in the conscious and reflective selection of specialized educational and informational offerings. MMT, however, does not claim to explain these usage aspects either. According to Zillmann (2000), the future goal would be to formulate multiple theories of focus on specific media genres within the framework of the selective exposure approach.

In contrast, we think that stimuli specific theories should not be the main focus of theory development in this field as media genres change gradually over decades and viewers differ in reacting emotionally to media content. Therefore, we see the solution in an integrative theoretical view on the formation of affects as well as on the motives and abilities to regulate them.

\section{Dimensions of an integrative view on affect regulation through media usage}

As a whole, MMT is a consistent theory with clear distinctions. It covers the hedonistic, unconscious, and unreflective selection of entertainment offerings in externally restricted stimulus arrangements. However, we feel a need to complement this perspective with other aspects of affect regulation deriving from contemporary theories of emotion (regulation) and mood (regulation) as well as from findings of communication studies. In all, we will discuss four aspects. First, we refer to MMT's unconscious, automatic selection behavior as regulation strategy and the necessity of considering conscious, reflected strategies and processes as well. In the second section, we discuss if there are, apart from hedonism, other motives instigating affect regulation. Thirdly, we present regulation strategies other than selection behavior that are examined and debated in publications on psychology of emotion, many of which have already been applied in media-related studies. Finally, we discuss the possibilities of how considering individual attributes can enrich an extended view on affect regulation through media usage.

\section{Unconscious, automatic regulation behavior and conscious, reflective regulation behavior}

In MMT, moods arise automatically, without the participation of cognitive or conscious processes. MMT also assumes learnt operant mechanisms, which the individual is not necessarily aware of. Even the hedonistic motives underlying mood regulation processes generally are not conscious (Zillmann, 1988, 2000). Emotion psychologists differentiate between unconscious and conscious processes, too (e. g., Frijda, 1993; Oehman, 1999). However, according to them, not only emotions and 
emotion regulation but also moods and mood regulation may become conscious. Moods - in contrast to emotions - are normally not directed towards an object, but there is an eliciting situation that the individual may be or may become more or less conscious of. Apart from that, Clore and Robinson (2000) suggest that moods (as emotions) have certain functions for the individual. Moods inform retrospectively about the hedonic value of recent life experiences and proactively about the prospects in particular areas. An automatic and unconscious regulation of moods would not be functional, or may even be obstructive, because possible reasons for a bad mood would stay undiscovered and therefore not repaired. Thus, the advantage of mood improvement would merely be of short term.

According to Morris (1992), conscious processes of mood regulation assume conscious monitoring and evaluation of the mood state. Monitoring and evaluation become conscious when there are considerable mood fluctuations, which force a person to look for an explanation and to act. Reflective and unreflective experiences are distinguished in the conscious mood experience. In the former, a person knows that he or she is in a certain mood, in the latter, a person only feels it. Situations in which we deny being in a certain mood in front of others are generally characterized by experiencing the mood unreflectively. Both forms of experience can occur in unison. One can feel a mood and be fully aware of it. A consciously and successfully applied strategy of mood regulation assumes both forms of experience; one can only regulate one's feelings in a positive sense if one is truly aware of them. Strategies for correcting moods make sense and are only possible if an unpleasant mood enters consciousness and becomes available for appraisal processes (Parkinson et al., 1996; Wirth and Schramm, 2007).

Meta-experience of mood (cf., Mayer and Gaschke, 1988; applied to sad film exposure: Oliver, 1993) should also be mentioned in this context. Here, we deal with the reflective perception and evaluation of mood. It encompasses, for example, the appraisal of whether a mood is acceptable, typical, or under control and whether it has or has not changed. These meta-appraisals explain why viewers differ in motives/strategies of mood regulation individually and situationally. For example, viewer A and viewer B both feel sad when watching a drama, but viewer A appraised this feeling as acceptable, typical, and 'under control', whereas viewer B appraised it as unacceptable and 'not under control'. As a consequence, viewer A probably would not regulate her/his mood at all, whereas viewer B would select another program, try to distract from the sad movie, or do something else to get control again over the situation (Bartsch, Mangold, Viehoff, and Vorderer, 2006; see for a appraisal theoretical model: Wirth and Schramm, 2007). 
Even in explaining the 'stronger' and therefore more consciously experienced emotions, Zillmann (2003) emphasizes the unconscious processes by referring to neurophysiological findings (LeDoux, 1998). Recent findings in neuroscience, however, confirm the view that emotional reactions comprise intense conscious cognitive processing (e. g., Phan, Wager, Taylor, and Liberzon, 2002) that is associated with higher activity in the left midfrontal cortical regions (Harmon-Jones, Sigelman, Bohlig, and Harmon-Jones, 2003). These regions are strongly involved in consciously motivated control processes (Beauregard, Levesque, and Bourgouin, 2001; Ochsner and Feldman Barrett, 2001). Even in first media-related studies that were based on functional magnetic resonance imaging (fMRI), cortical activities were measured during viewing of emotional media sequences (Anderson, Fite, Petrovich, and Hirsch, 2006; Murray, Liotti, Ingmundson, Mayberg, Pu, Zamarripa et al., 2006).

We do not claim that there are no unconscious mood/emotion phases at all. Such phases probably involve less deliberate and more automatic regulation strategies that are already developed in the early childhood. Cantor (1994), for example, found developmental differences in the effectiveness of strategies for regulating media-induced fright reactions. Noncognitive, automatic regulation strategies are still more effective for preschool children, whereas older elementary school children benefit more from strategies with a deliberate, cognitive component. However, it is difficult to make automatic regulation processes consistent with the assumptions of MMT because in the case of negative moods, they lead more to mood congruency rather than mood repair. Moods have the tendency to push psychological processes into a direction that is consistent with its evaluative content. According to this tendency (known as mood-congruency hypothesis), "people selectively attend to, interpret, and remember information that is similar in emotional tone to their current mood state" (Rusting, 2001, p. 372). This hypothesis can be regarded as empirically well confirmed (Forgas, 2002; Rusting, 2001). Forgas and Ciarrochi (2002, p. 336) summarize: "There is now clear evidence to suggest that mood has a strong mood-congruent influence on a wide variety of social judgments and behavior." Mood congruency usually occurs when there is no particular motivation for mood repair (Erber and Erber 2000a, 2000b; Erber, Wegner, and Therriault, 1996; Krohne, Pieper, Knoll, and Breimer, 2002).

The theoretical background for mood-congruency is the network theory of affect (Bower, 1981; Forgas, 1999). Forgas and his colleagues deal specifically with mood effects on cognitive processes that are certainly not identical with selection decisions as described in the framework of MMT. However, one can assume that behavioral (e. g., selection behavior) and cognitive processes in mood regulation do not simulta- 
neously point to completely different directions (e. g., the cognitive processes in direction of mood maintenance, the selective actions in direction of mood repair and vice versa). Instead, cognitive processes likely occur in the background of behavioral processes, which are, as far as the direction is concerned, usually consistent with the behavior (cf. Bargh and Ferguson, 2000; Gollwitzer and Bargh, 1996). This implies that sadness would not only affect congruent cognitions but would also affect congruent behavior. Regarding MMT, sad viewers would consequently select more sad than cheering media offerings. Thus, mood-congruency hypothesis and mood-management hypothesis are contradictory and cannot be tested at the same time.

However, according to a recently developed theory by Forgas and coworkers, a temporal sequence can emerge in which, during the first minutes after mood induction, cognitive processes first lead to moodcongruent regulation strategies and then (after a while) to mood-incongruent regulation strategies (Forgas, 1999, 2001; Forgas, Ciarrochi, and Moylan, 2000). Forgas and Ciarrochi (2002) have presented empirical results that confirm these assumptions. In order to apply these findings to selection processes, it may be advantageous to take the temporal dimension into consideration and to differentiate the theory accordingly. Namely, selection processes immediately following mood induction can be quite different from those following a few minutes later. Mood-congruent thinking and selection processes may be the result of automatic mood effects, and mood-incongruent thinking and selection processes may result from subsequent more or less conscious mood management. In summary, it may be worthwhile to distinguish between early unconscious (automatic) mood effects and subsequent conscious (and more or less controlled) mood effects (cf. Oehman, 1999; Lambie and Marcel, 2002).

\section{Hedonism and other motives of action impulse}

A central assumption of MMT is that human beings are hedonistic by nature and will therefore minimize or avoid unpleasant stimulations/ moods and maximize or perpetuate pleasant stimulations/moods (Zillmann, 1988). Other authors do not regard the hedonism hypothesis as unconditionally confirmed. Knobloch's (2003) mood-adjustment approach incorporates Zillmann's (2000) ideas as well as various empirical findings concerning mood adjustment in non-media contexts. According to this approach, individuals do not try to improve their mood and to render it positive in every case, but to adjust their mood depending on an actual or future social situation and on momentary activities. Knobloch (2003) showed that individuals prepare their mood for a task- 
adequate optimal level in anticipation for actions and tasks waiting for them in the future by using appropriate music. Erber, Wegner and Therriault (1996), for instance, found that persons who expect social interaction with others try to attenuate their mood by selecting newspaper articles with a valence opposite to their mood. The authors interpreted the intended neutral mood as an appropriate state when anticipating an unknown social situation. This is a clear contradiction to the assumptions of MMT. Other authors also argue for alternative motors of affect regulation than hedonism (cf. even Zillmann, 1998, 2000). Parrott (1993) lists twelve motives explaining why individuals maintain bad moods and another twelve motives explaining why they avoid good moods. The automatic and immediate affect regulation, he says, is dysfunctional because affect provides valuable information about the situation that an individual may find him or herself in. Therefore, immediate mood improvement may be welcome from a hedonistic point of view, but it may often be functionally suboptimal (Erber, Wegner, and Therriault, 1996; Knobloch, 2003). Schramm (2005), for example, found out that people being in sadness often want to listen to sad, not joyful music because they even want to enforce their mood and wallow in the mood to intensively process the problem that caused the sadness. Clore and Robinson (2000) also question the heuristic value of the hedonism premise for similar reasons. To them, instrumental goals are more powerful than hedonistic goals. Hedonistic goals are good moods and pleasure, while instrumental goals are success; the optimization of profit and the satisfaction experienced when a goal that has been reached. One can argue that such instrumental goals ultimately serve hedonistic goals, since individuals strive for a good mood by reaching their goals. However, such a 'delayed' hedonism hypothesis is empirically problematic because it cannot readily be falsified. That is, any behavior may be interpreted as either directly or indirectly hedonistic (Clore and Robinson, 2000).

Waterman (1993) gave another alternative to the hedonism hypothesis: the eudaimonic hypothesis (see also Ryan and Deci, 2001). According to the eudaimonic hypothesis, the goal is not immediate or delayed pleasure, but a self-determined life in conformity to one's own values and identity. Fundamental to eudaimonic striving is a different conception of well-being than in hedonistic striving. Whereas hedonistic well-being is primarily associated with the presence of positive mood and the absence of problems and negative mood, eudaimonic well-being is associated with feelings of challenge and effort (Waterman, 1993). Although the eudaimonic hypothesis has yet to be tested with media stimuli, according to this assumption, challenging, sophisticated media offerings should be selected independently of the current mood state. By all means, these can be (sophisticated) entertainment offerings, too. 
Our recommendation is not to substitute the hedonism premise with alternative premises. Instead, we believe that considering both hedonism and alternative selection principles (such as instrumental goal orientation or the eudaimonic hypothesis) may be helpful in order to better understand affect regulation through media usage (for a similar argumentation see even Zillmann, 2000).

\section{Selection behavior and other regulation strategies}

In MMT, Zillmann is concerned with mood regulation via selection of media content. In publications pertaining to the psychology of emotion, however, one can find numerous strategies of affect regulation. They can be classified according to different criteria whereas the distinction between behavioral and cognitive strategies is the most central criterion (cf. e. g., Gross, 1999; Larsen, 2000; Morris and Reilly, 1987; Thayer, Newman, and McClain, 1994). Parkinson et al. (1996) collected examples from various sources and distinguished 200 cognitive and behavioral strategies (including media selection behavior). In media-related studies, cognitive and behavioral regulation strategies are differentiated as well (e. g., Cantor, 1994; Harrison and Cantor, 1999; Hoffner, 1995; Wilson, Hoffner, and Cantor, 1987; for an overview: Cantor, 2002). Harrison and Cantor (1999), for example, found out that children at the age of seven or younger use behavioral strategies in almost every situation $(87.5 \%)$ when they are confronted with scary media content, whereas children between eight and twelve years choose them in $66.7 \%$ of all scary media situations, and children at the age of 13 and older in only $42.3 \%$ of all scary media situations. By-and-by, children learn that cognitive strategies are often more adequate to regulate negative affect in a sensitive and constructive way.

Cognitive regulation strategies explain a relevant part of the attention to the media as well as the way we deal with the media; especially when affect arises during media reception. If a media content is too stressful, viewers often reinterpret the media situation (cognitive reappraisal) or change the situational reference of appraisal by switching, for example, from a socio-emotional perspective with focus on the protagonist to a ego-emotional perspective with focus on own considerations (Wirth, Schramm, and Boecking, 2006; Wirth and Schramm, 2007). Even with respect to selective behavior, it is questionable that this behavior is traced back exclusively to operant learning. Instead, the behavior could be associated with cognitive strategies before and during media consumption (Gross, 1999; in the context of media usage: Nabi, 2006). As already mentioned above, regulation strategies can be classified according to different criteria. Larsen (2000) emphasizes that regulation strategies could 
not only aim at 'directly' changing the person's actual mood by changing, for example, the cause for the mood, but also 'indirectly' at the current situation. For example, persons can try to shield the mood for a while, or in certain situations, try to distract themselves or to interpret the situation positively through cognitive reframing. Mood management, according to Zillmann's conceptualization, falls into this category. $\mathrm{He}$ describes a regulation behavior that does not primarily attempt to change the person's cause for a mood, but rather to change the situation; at least for the time of reception because the mood-eliciting problem is rarely processed or even solved. According to Gross (2002), people sometimes fall back into their initial mood they had before media consumption because they only suppress their affect temporarily. One can hypothesize that such effects occur less frequently when media selection is more deliberate and the media content is processed more consciously in terms of affect regulation, because the media are used for processing the mood in a more sustainable way. Another category of regulation strategies becomes obvious on the background of Gross's emotion-regulation theory (Gross, 1999). Gross not only describes the 'usual' response-focused affect regulation strategies such as suppression, rumination, or reappraisal, but also the antecedent-focused strategies, which are evident in situation selection and in situation modification. Situation selection refers to initially avoiding certain persons, places or objects, which would lead to an undesired emotion change. Situation modification describes a strategy through which a person tries to prevent potentially undesirable emotions in a given situation by selecting circumstances most favorable to him or her among the given possibilities and degrees of freedom within the situation. These strategies can both be adapted to media usage or media selection behavior. A person may switch on the TV to pay motivated attention to a specific media offering or to avoid something, for example, another media offering, or someone, for example a member of the family (situation selection). Once the TV is switched on, staying tuned to a program could be explained by its mood-improving effect or by the conscious non-switching to an alternative supposedly mood-impairing program (situation modification). Thus, an integration of these antecedent-focused regulation strategies along with a differentiation of response-focused regulation strategies (selection behavior is only a specific form of them) seems to be strongly recommendable and fruitful in explaining affect regulation through media usage.Finally, negative affects must not always necessarily be regulated, but may instead be maintained consciously for some good reason (e. g., in order to understand oneself in a better way). Although the term 'nonregulation' is often used for this phenomenon erroneously, it is impor- 
tant to recognize that the constant negative mood may be the result of a regulation strategy (cf., Gross, 1999, p. 565; in the context of sad films: Oliver, 1993; in context of sad music: Schramm, 2005).

\section{Systematic integration of individual attributes}

Individual differences are not part of MMT in its early version. However, Zillmann (2000) more recently describes several empirically established relations between individual attributes (e. g., gender) and general media preferences. He subsequently questions the importance of these findings though because, in his opinion, they do not provide insights on the relation between situational media selection and mood repair. Finally, he indicates that ".. it will be necessary to go beyond the assessment of choices by personality alone and to examine media choices as a joint function of both enduring traits and situationally determined moods" (Zillmann, 2000, p. 113). Going beyond media preferences, we would like to describe the relations between individual attributes and affect regulation in a systematic manner. Here, we want to concentrate on those attributes that have a high affinity to affect regulation, that is, we will discuss individual differences in affective experiences, in the motivation for affect regulation, and in affect regulation competency/performance.

First of all, it seems obvious to search for individual differences in experiencing and in dealing with affects, which could either have a reinforcing or an attenuating influence on affect regulation tendencies (Rusting, 2001). Newhagen (1998) and Nabi (2003), for example, found that different affects (e. g., anxiety/anger) that are evoked by media offerings result in different action tendencies (e. g., flight/attack behavior) that are correlated with regulation strategies (e. g., repressing/sensitizing). However, these tendencies and corresponding regulation strategies differ individually and situationally as people vary in their former experiences with and affinity to these affective states (Cantor, 2002; Sparks, Spirek, and Hodgson, 1993; Sparks and Sparks, 2002).

Extraverted persons, for example, report having more frequent and more intense affects than introverted persons; and persons with high neuroticism report having negative affects more frequently and more intensely (Rusting and Larsen, 1997; Watson and Clark, 1992). Rusting (2001) argues that persons with a tendency for extraversion or neuroticism are more sensitive to positive or negative information and that such information is therefore processed more frequently and more intensely. With reference to Bower's (1981) network theory, she concludes that mood-congruent behavior is more probable for these subgroups than for low-extraversion or low-neuroticism individuals. In a series of experi- 
ments she confirmed her hypothesis empirically (Rusting, 2001). In contrast to the assumptions of MMT, one can hypothesize that high-neurotic individuals in a negative mood would select mood-congruent offerings and offerings with a semantic affinity to the current mood. Schramm (2005), for example, found that people in sadness want to listen the more to sad music the more they are neurotic. Similarly, other researchers found that variables such as neuroticism and psychoticism are correlated with favorability ratings on violent media content (e.g., Zillmann and Weaver, 1997).

In publications by Erber and coworkers (Erber and Erber, 2000a, 2000b; Erber, Wegner, and Therriault, 1996), the importance of individual motivational variables for affect regulation became evident. The study of Knobloch (2003), as well as the 'mood-management versus socialcomparison' study by Mares and Cantor (1992) could be interpreted in this sense, too. The latter showed that lonely elderly people were more motivated to watch negative portrayals of old age than non-lonely people because they could improve their bad mood by downward comparison. Such results indicate that it is plausible to look for individual differences in the motivation for affect regulation. In this context, we should primarily mention coping styles, particularly vigilance and cognitive avoidance, which are two contrasting strategies in dealing with stressful situations. Cognitive avoidance is turning away from a threatening situation, whereas vigilance means turning towards stressful aspects of the situation (Krohne, 2001). Similar concepts are sensitization versus repression (Byrne, 1964; in the context of media usage cf. Sparks, Pellechia, and Irvine, 1999; Vitouch, 2007) and monitoring versus blunting (Hoffner, 1993; Miller, 1987; in the context of media usage cf. Hoffner, 1995, 1997). Cognitive avoiders should be motivated to stay away from negative moods or to attenuate them by distracting themselves. For instance; in a negative mood they should show mood-incongruent selection behavior. In contrast, vigilants should be less likely to strive to attenuate a negative mood, but should rather attempt to get to know more about the situation that is enhancing the negative mood, or generally to get an overview of possible causes for the negative mood. Consequently, when these individuals are in a negative mood, one should observe moodcongruent and semantically affine selection behavior. First empirical support for these hypotheses exists (Krohne, 2003; Krohne et al., 2002; in the context of media usage cf. for overviews: Cantor, 2002; Sparks and Sparks, 2002; Vitouch, 2007).

With respect to other motivational aspects, individuals may also differ in expectancies of more or less successful affect regulation (Catanzaro and Mearns, 1999). Negative mood regulation expectancies represent beliefs individuals have that when they are in a bad mood, they can do 
something to make themselves feel better. Rusting and DeHart (2000; Rusting, 2001) showed that persons with high values on this dimension were more successful in attenuating their negative moods; in strategies of mood maintenance (e. g. rumination) as well as in strategies of mood repair (e.g. distraction).

Individual differences in affect regulation may occur, even if the emotional experience and the motivation for affect regulation are identical. Thus, individual differences in competency, performance and, consequently, success in affect regulation need to be considered. Individual differences in ability to monitor and name affects could influence the success of affect-regulating measures. Individuals get information about their current affect state from different sources. They perceive physiological changes in the body and interpret these as an indicator of an affect state; they observe their own mimetic feedback and make inferences on their well-being; they register their posture as well as their own behavior; and they draw conclusions on their current affects. In addition, they receive signals and reactions from others that can provide feedback on their affect state. Therefore, affect monitoring and affect labeling are critical for the correct 'translation' of this information into the conscious cognizance of their affect state, although individuals can have the ability to attend to their affects and to monitor them critically without having the ability to identify and label them adequately. Thus, individuals can be skilled 'affect monitors' without being skilled 'affect labelers' (Parkinson et al., 1996). Results (e.g., Swinkels and Giuliano, 1995) indicate that skilled affect labelers seem to be more apt to get out of a bad mood or to maintain a good affect. In contrast, skilled affect monitors react more sensitively to events, and are thus more often in a bad affect and are more likely to consider their own affect regulation to be less successful than such of unskilled affect monitors. Skilled affect monitors tend more strongly to use regulation strategies, which are characterized by musing or by 'circling' around the negative aspects of a situation. Strong affect monitoring initiates regulation strategies that lead to mood deterioration in the short term and, at best, to affect improvement in the long term, whereas, an intensive affect labeling results in more productive strategies that may also improve the affect in the short term. Other individual competency effects are indicated, for example, by findings of a study of Feldman Barrett, Gross, Christensen, and Benvenuto (2001). Persons who have a broad and differentiated emotional experience are also more successful in negative affect regulation.

Although this brief discussion of individual attributes may be far from complete, it indicates the necessity to incorporate such individual/personality attributes into a potential integrative theory of affect regulation through media usage. 


\section{Conclusion}

The aim of this contribution was to underline the need for an integrative view on affect regulation through media usage. For us, the first critical question is whether the extension of MMT or the formulation of several specific affect regulation theories would be more productive. Zillmann (2000) recommends leaving MMT unchanged as a theory for selecting entertainment programs and to develop further specialized theories (e.g., for the selection of educational and informational programs). In our opinion, this would not be the best solution. Considering MMT as an example, it is primarily formulated for externally restricted stimulus arrangements of entertainment offerings (Zillmann, 1988). However, this restricted entertainment arrangement seems to be a rare exception if one takes the diversity of media offerings into consideration. Furthermore, we do perceive a general disadvantage in formulating specialized affect regulation theories for specific media stimuli, as such a strategy would make it difficult to examine whether regulation strategies that are theoretically attributed to information programs can be applied to entertainment programs or vice versa. Finally, a genre specific theory development in the domain of affect regulation would not be useful because, in recent decades, entertainment and information programs on TV and other media have been merging in a variety of ways (soundbite news, infotainment, reality shows). Thus, a clear separation between entertainment-related and information-related affect regulation theories would be problematic. From this perspective, the only solutions - in our view would be an extension of MMT (like Knobloch's mood-adjustment approach, 2003) or a completely new integrative theory of affect regulation.

In summary, what would be the requirements for such an integrative theory of affect regulation through media? A first postulate concerns the integration of unconscious/automatic and conscious/reflective regulation processes. Since, in emotion research, both kinds of processes play a role in both groups of affect (mood and emotion), affect regulation should not restrict itself to unconscious processes. At the same time, it should be emphasized that unconscious processes are certainly more relevant for mood regulation than for emotion regulation. As Zillmann and colleagues concentrated on unconscious, automatic processes, they inferred these processes from the 'objectively' observed media selections of their subjects. Consequently, they avoided subjective measurements like questionnaires and self-reports because subjects would not be able to report their initial moods and following regulation processes. In contrast, conscious/reflective regulation processes should be accessible for such subjective measurements to a great extent (Oehman, 1999; Schramm, 2005). One of the most challenging tasks for future research in this area will be 
to measure both forms of regulations processes; ideally even within the same study.

Additionally, an integrative theory would not be restricted to hedonism as an action impulse, but take other instrumental motives into account, such as eudaimonic well-being, sensation seeking, rumination, or sensitization (e. g., Ryan and Deci, 2001). Also, it should include situational influences that lead to mood adjustment (Knobloch, 2003). As previous research has already shown, meta-emotions as results of metaappraisals could play a relevant role in such instrumentally motivated regulation processes as well as in delayed mood changes. Thus, we should be able to benefit from already existing instruments for measuring meta-appraisals and meta-emotions (e. g., Mayer and Gaschke, 1988; Oliver, 1993).

By extending the hedonism motive to a broad set of regulation strategies, it seems advisable to include mood-focused and situation-focused regulation strategies (Larsen, 2000) as well as behavioral and cognitive regulation strategies (Cantor, 2002; Morris and Reilly, 1987). Emotionantecedent regulation strategies (Gross, 1999) could be considered as well. Anyway, strategies of affect regulation through media usage must be more encompassing than selection behavior.

Apart from that, the individual differences already mentioned by Zillmann (2000) must be systematically expanded and incorporated into an integrative theory. Attention should be directed towards 'more affectspecific' rather than towards 'more general' individual attributes by including (a) differences in the experience of and the dealing with affect, (b) differences in the motivation for affect regulation, and (c) differences in affect regulation competency, performance and efficiency.

Finally, such an integrative approach should not merely have either mood regulation or emotion regulation as its subject, as it should contain and explain both. It cannot, finally, be determined whether mood regulation and emotion regulation can be differentiated in all parts of such an approach, as the majority of the current studies did not make such a distinction. The state of empirical research is still too fuzzy or too undifferentiated to convincingly argue that, for example, specific regulation strategies may only be applied to emotion regulation and not to mood regulation. Nevertheless, the state of theoretical research suggests a differentiation between mood and emotion and holds arguments for different processes of mood regulation and emotion regulation (e. g., Frijda, 1993; Lambie and Marcel, 2002; Oehman, 1999).

An integrative theory of affect regulation through media usage should also differ from a general view on affect regulation by not only treating media usage as a means of affect regulation or (as in MMT) as a response to affect, but also as a cause. Not only does the need to regulate affect 
lead to media usage, but media usage itself also produces affect that needs to be regulated either during or after media usage (Bartsch et al., 2006; Schramm, 2005; Wirth, Schramm, and Boecking, 2006; Wirth and Schramm, 2007). Admittedly, such an integrative theory is very ambitious and even more challenging when it comes to its empirical implementation. Nevertheless, previous studies from communications as well as from media psychology and emotion psychology should give us the necessary basics to cope with this challenge.

Finally, it should be emphasized once more that such an integrative view is not meant to restrict the validity of MMT (cf. already Zillmann, 2000). MMT is a consistent theory. Based on Zillmann's own threefactor theory of mood/emotion (2003) and on hedonism as dominant premise, MMT certainly leads to very good prognoses for a part of our daily media selections. However, as far as we know, no one has tried to build upon MMT using other theories of mood regulation and emotion regulation in order to work towards a coherent, integrative, and comprehensive theory. Perhaps our arguments can serve as a first step towards a broader theory that would lead to even better prognoses of affect regulation through media usage.

\section{Note}

1. Moods and emotions are subordinate categories to affect, but should be distinguished from one another. Parkinson, Totterdell, Briner, and Reynolds (1996) have summarized the main distinctions between the two kinds of affect on six levels. Emotions are elicited by a specific event or cause (the onset is therefore fast and episodic in specific situations), are directed intentionally towards a concrete object or goal, are of relatively short duration (generally not longer than a few minutes), and are relatively intense. In contrast, moods are fuzzier affective states: their duration is relatively long, and their intensity is rather weak. The onset is gradual (they develop continuously), they are not directed towards a concrete object/goal, and they are not determined by a specific situation, but rather by the current psychological state of the person.

\section{References}

Anderson, D. R., Fite, K. V., Petrovich, N., and Hirsch, J. (2006). Cortical activation while watching video montage: An fMRI study. Media Psychology, 8, 7-24.

Bargh, J. A., and Ferguson, M. L. (2000). Beyond behaviorism: On the automaticity of higher mental processes. Psychological Bulletin, 126, 925-945.

Bartsch, A., Mangold, R., Viehoff, R., and Vorderer, P. (2006). Emotional gratifications during media use - an integrated approach. Communications - the European Journal of Communication Research, 31, 261-278.

Beauregard, M., Levesque, J., and Bourgouin, P. (2001). Neural correlates of conscious self-regulation of emotion. The Journal of Neuroscience, 21, RC165(1-6).

Bower, G. H. (1981). Mood and memory. American Psychologist, 36, 129-148. 
Byrne, D. (1964). Repression-sensitization as a dimension for personality. In B. A. Amher (Ed.), Progress in experimental personality research (Vol. 1, pp. 169-220). New York: Academic Press.

Cantor, J. (1994). Children's fright reactions to television and films. Poetics, 23, 75-89.

Cantor, J. (2002). Fright reactions to mass media. In J. Bryant and D. Zillmann (Eds.), Media effects. Advances in theory and research (pp. 287-306). Mahwah, NJ: Lawrence Erlbaum Associates.

Catanzaro, S. J., and Mearns, J. (1999). Mood-related expectancy, emotional experience, and coping behavior. In I. Kirsch (Ed.), Expectancy, experience and behavior (pp. 67-91). Washington, DC: American Psychological Association.

Clore, G. L., and Robinson, M. D. (2000). What is emotion regulation? In search of a phenomenon. Psychological Inquiry, 11, 163-166.

Erber, R., and Erber, M. W. (2000a). Mysteries of mood regulation, part II: The case of the happy thermostat. Psychological Inquiry, 11, 210-213.

Erber, R., and Erber, M. W. (2000b). The self-regulation of moods: Second thoughts on the importance of happiness in everyday life. Psychological Inquiry, 11, 142148.

Erber, R., Wegner, D. M., and Therriault, N. (1996). On being cool and collected: Mood regulation in anticipation of social interaction. Journal of Personality and Social Psychology, 70, 757-766.

Feldman Barrett, L., Gross, J., Christensen, T. C., and Benvenuto, M. (2001). Knowing what you're feeling and knowing what to do about it. Mapping the relation between emotion differentiation and emotion regulation. Cognition and Emotion, $15,713-724$.

Forgas, J. P. (1999). Network theories and beyond. In T. Dalgleish and M. Power (Eds.), The handbook of cognition and emotion (pp. 591-612). Chichester: Wiley.

Forgas, J. P. (2001). Managing moods: Toward a dual-process theory of spontaneous mood regulation. Psychological Inquiry, 11, 172-177.

Forgas, J. P. (2002). Feeling and Doing: Affective influences on interpersonal behavior. Psychological Inquiry, 13, 1-28.

Forgas, J. P., and Ciarrochi, J. V. (2002). On managing moods: Evidence for the role of homeostatic cognitive strategies in affect regulation. Personality and Social Psychology Bulletin, 28, 336-345.

Forgas, J. P., Ciarrochi, J. V., and Moylan, S. J. (2000). Subjective experience and mood regulation: The role of information processing strategies. In $\mathrm{H}$. Bless and J. P. Forgas (Eds.), The message within: Subjective experiences and social cognition (pp. 179-202). Philadelphia: Psychology Press.

Frijda, N. H. (1993). The place of appraisal in emotion. Cognition and Emotion, 7, $357-387$.

Gollwitzer, P. M., and Bargh, J. A. (Eds.). (1996). The psychology of action: Linking motivation and cognition to behavior. New York: Guilford Publications.

Gross, J. J. (1999). Emotion regulation: Past, present, future. Cognition and Emotion, $13,551-573$.

Gross, J. J. (2002). Emotion regulation: Affective, cognitive, and social consequences. Psychophysiology, 39, 281-291.

Harmon-Jones, E., Sigelman, J. D., Bohlig, A., and Harmond-Jones, C. (2003). Anger, coping, and frontal cortical activity: The effect of coping potential on anger-induced left frontal activity. Cognition and Emotion, 17, 1-24.

Harrison, K., and Cantor, J. (1999). Tales from the screen: Enduring fright reactions to scary media. Media Psychology, 1, 97-116.

Hoffner, C. (1993). Children's strategies for coping with stress: Blunting and monitoring. Motivation and Emotion, 17, 91-106. 
Hoffner, C. (1995). Adolescents' coping with frightening mass media. Communication Research, 22, 325-346.

Hoffner, C. (1997). Children's emotional reactions to a scary film: The role of prior outcome information and coping style. Human Communication Research, 23, $323-341$.

Knobloch, S. (2003). Mood adjustment via mass communication. Journal of Communication, 53, 233-250.

Knobloch, S., and Zillmann, D. (2002). Mood management via the digital jukebox. Journal of Communication, 52, 351-366.

Krohne, H. W. (2001). Stress and coping theories. In N. J. Smelser and P. B. Baltes (Eds.), The international encyclopedia of the social and behavioral sciences (Vol. 22, pp. 15163-15170). Oxford, UK: Elsevier.

Krohne, H. W. (2003). Individual differences in emotional reactions and coping. In R. J. Davidson, K. R. Scherer, and H. H. Goldsmith (Eds.), Handbook of affective sciences (pp. 698-725). New York: Oxford University Press.

Krohne, H. W., Pieper, M., Knoll, N., and Breimer, N. (2002). The cognitive regulation of emotions: The role of success versus failure experience and coping dispositions. Cognition and Emotion, 16, 217-243.

Lambie, J. A., and Marcel, A. J. (2002). Consciousness and the varieties of emotion experience: A theoretical framework. Psychological Review, 109, 219-259.

Larsen, R. J. (2000). Toward a science of mood regulation. Psychological Inquiry, 11, $129-141$.

LeDoux, J. (1998). The emotional brain. The mysterious underpinnings of emotional life. New York: Touchstone.

Mares, M.-L., and Cantor, J. (1992). Elderly viewers' responses to televised portrayals of old age. Empathy and mood management versus social comparison. Communication Research, 19, 469-478.

Mayer, J. D., and Gaschke, Y. N. (1988). The experience and meta-experience of mood. Journal of Personality and Social Psychology, 55, 102-111.

Miller, S. M. (1987). Monitoring and blunting: Validation of a questionnaire to assess styles of information seeking under threat. Journal of Personality and Social Psychology, 52, 345-353.

Morris, W. N. (1992). A functional analysis of the role of mood in affective systems. In M. S. Clark (Ed.), Emotion (Review of Personality and Social Psychology, Vol. 13, pp. 256-293). Newbury Park, CA. Sage.

Morris, W. N., and Reilly, N. P. (1987). Toward the self-regulation of mood: Theory and research. Motivation and Emotion, 11, 215-249.

Murray, J. P., Liotti, M., Ingmundson, P. T., Mayberg, H. S., Pu, Y., Zamarripa, F., Liu, Y., Woldorff, M. G., Gao, J.-H. and Fox, P. T. (2006). Children's brain activations while viewing televised violence revealed by fMRI. Media Psychology, 8 , $25-37$.

Nabi, R. L. (2003). Exploring the framing effects of emotion. Do discrete emotions differentially influence information accessibility, information seeking, and policy preference? Communication Research, 30, 224-247.

Nabi, R. L. (2006). The Coping with Discrete Emotions (CoDE) Model of TVIMedia Exposure. Presentation at the Annual Conference of the International Association Communication, June 19-23, Dresden, Germany.

Newhagen, J. E. (1998). TV news images that induce anger, fear, and disgust: Effects on approach-avoidance and memory. Journal of Broadcasting and Electronic Media, 42, 265-276.

Ochsner, K. N., and Feldman Barrett, L. (2001). A multiprocess perspective on the neuroscience of emotion. In T. J. Mayne and G. Bonnanno (Eds.), Emotion: Current issues and future directions (pp. 38-81). New York: Guilford Press. 
Oehman, A. (1999). Distinguishing unconscious from conscious emotional processes: Methodological considerations and theoretical implications. In T. Dalgleish and M. Power (Eds.), Handbook of cognition and emotion (pp. 321-352). John Wiley and Sons Ltd.: West Sussex.

Oliver, M. B. (1993). Exploring the paradox of the enjoyment of sad films. Human Communication Research, 3, 315-342.

Oliver, M. B. (2003). Mood management and selective exposure. In J. Bryant, D. Roskos-Ewoldsen, and J. Cantor (Eds.), Communication and emotion: Essays in honor of Dolf Zillmann (pp. 85-106). Mahwah, NJ: Lawrence Erlbaum Associates.

Oliver, M. B., Weaver, J. B., and Sargent, S. (2000). An examination of factors related to sex differences in enjoyment of sad films. Journal of Broadcasting and Electronic Media, 44, 282-300.

Parkinson, B., Totterdell, P., Briner, R. B., and Reynolds, S. (1996). Changing moods. The psychology of mood and mood regulation. New York: Addison Wesley Longman.

Parrott, W. G. (1993). Beyond hedonism: Motives for inhibiting good moods and for maintaining bad moods. In D. M. Wegner and J. W. Pennebaker (Eds.), Handbook of mental control (pp. 278-305). Englewood Cliffs, NJ: Prentice-Hall.

Phan, K. L., Wager, T., Taylor, S. F., and Liberzon, I. (2002). Functional Neuroanatomy of Emotion: A Meta-Analysis of Emotion Activation Studies in PET und fMRI. NeuroImage, 16, 331-348.

Rusting, C. L. (2001). Personality as a moderator of affective influences on cognition. In J. T. Forgas (Ed.), Handbook of affect and social cognition (pp. 371-391). Mahwah, NJ: Lawrence Erlbaum Associates.

Rusting, C. L., and DeHart, T. (2000). Retrieving positive memories to regulate negative mood: Consequences for mood-congruent memory. Journal of Personality and Social Psychology, 78, 737-752.

Rusting, C. L., and Larsen, R. J. (1997). Extraversion, neuroticism, and susceptibility to positive and negative affect: A test of two theoretical models. Personality and Individual Differences, 22, 607-612.

Ryan, R. M., and Deci, E. L. (2001). On happiness and human potentials: A review of research on hedonic and eudaimonic well-being. Annual Review of Psychology, $52,141-166$.

Schachter, S., and Singer, J. (1962). Cognitive, social, and physiological determinants of emotional state. Psychological Review, 69, 379-399.

Schramm, H. (2005). Mood Management durch Musik. Die alltaegliche Nutzung von Musik zur Regulierung von Stimmungen [Mood management by music. The daily use of music for mood regulation]. Cologne, Germany: Halem.

Sparks, G. G., Pellechia, M., and Irvine, C. (1999). The repressive coping style and fright reactions to mass media. Communication Research, 26, 176-192.

Sparks, G. G., and Sparks, C. W. (2002). Effects of media violence. In J. Bryant and D. Zillmann (Eds.), Media effects. Advances in theory and research (pp. 269-285). Mahwah, NJ: Lawrence Erlbaum Associates.

Sparks, G. G., Spirek, M. M., and Hodgson, K. (1993). Individual differences in arousability: Implications for understanding immediate and lingering emotional reactions to frightening mass media. Communication Quarterly, 41, 465-476.

Swinkels, A., and Giuliano, T. A. (1995). The measurement and conceptualization of mood awareness: Attention directed towards ones mood states. Personality and Social Psychology Bulletin, 21, 934-949.

Thayer, R. E., Newman, J. R., and McClain, T. M. (1994). Self-regulation of mood: Strategies for changing a bad mood, raising energy, and reducing tension. Journal of Personality and Social Psychology, 67, 910-925. 
Vitouch, P. (2007). Fernsehen und Angstbewaeltigung. Zur Typologie des Zuschauerverhaltens (3. Auflage) [Television and coping with fear. Types of viewer reactions (3rd edition)]. Wiesbaden, Germany: Verlag fuer Sozialwissenschaften.

Waterman, A. S. (1993). Two conceptions of happiness: contrasts of personal expressiveness (eudaimonia) and hedonic enjoyment. Journal of Personality and Social Psychology, 64, 678-691.

Watson, D., and Clark, L. A. (1992). On traits and temperament: General and specific factors of emotional experience and their relation to the five-factor model. Journal of Personality, 60, 441-476.

Weaver, J., and Tamborini, R. (Eds.). (1996). Horror films: Current research on audience preferences and reactions. Mahwah, NJ: Lawrence Erlbaum Associates.

Wilson, B. J., Hoffner, C., and Cantor, J. (1987), Children's perceptions of the effectiveness of techniques to reduce fear from mass media. Journal of Applied Developmental Psychology, 8, 39-52.

Wirth, W., and Schramm, H. (2005). Media and Emotions. Communication Research Trends, 24, 3-39.

Wirth, W., and Schramm, H. (2007). Emotionen, Metaemotionen und Regulationsstrategien bei der Medienrezeption. Ein integratives Modell. [Emotions, meta-emotions and emotion regulation during media consumption. An integrative model.] In W. Wirth, H.-J. Stiehler and C. Wuensch (Eds.), Dynamisch-transaktional denken: Theorie und Empirie in der Kommunikationswissenschaft [Thinking in a dynamic-transactional way: Theory and empirical research in communication science.] (pp. 153-184). Cologne, Germany: Halem.

Wirth, W., Schramm, H., and Boecking, S. (2006). Emotionen bei der Rezeption von Unterhaltung. Eine Diskussion klassischer und aktueller Ansätze zur Erklärung medial vermittelter Emotionen. [Emotion and reception of entertainment. A discussion of classic and contemporary approaches of media emotions]. In B. Frizzoni and I. Tomkowiak (Eds.), Unterhaltung: Konzepte - Formen - Wirkungen [Entertainment: Concepts - Forms - Effects] (pp. 221-246). Zurich, Switzerland: Chronos.

Zillmann, D. (1988). Mood management: Using entertainment to full advantage. In L. Donohew, H. E. Sypher, and E. T. Higgins (Eds.), Communication, social cognition, and affect (pp. 147-171). Hillsdale, NJ: Lawrence Erlbaum Associates.

Zillmann, D. (1998). Does tragic drama have redeeming value? Siegener Periodikum fuer Internationale Literaturwissenschaften, 16, 1-11.

Zillmann, D. (2000). Mood management in the context of selective exposure theory. In M. E. Roloff (Ed.), Communication Yearbook 23 (pp. 103-123). Thousand Oaks, CA: Sage.

Zillmann, D. (2003). Theory of affective dynamics: Emotions and moods. In J. Bryant, D. Roskos-Ewoldsen, and J. Cantor (Eds.), Communication and emotion: Essays in honor of Dolf Zillmann (pp. 533-567). Mahwah, NJ: Lawrence Erlbaum Associates.

Zillmann, D., and Weaver, J. B. (1997). Psychoticism in the effect of prolonged exposure to gratuitous media violence on the acceptance of violence as a preferred means of conflict resolution. Personality and Individual Differences, 22, 613-627. 